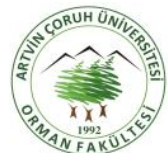

\title{
Kara Ardıç (Juniperus sabina L.) kozalaklarından elde edilen uçucu yağın kimyasal bileşimi üzerine mikrodalga ve hidrodestilasyon yöntemlerinin etkisi
}

\section{The effect of microwave and hydrodestillation methods on the chemical composition of essential oil obtained from juniper cones}

\author{
Murat ERTAŞ ${ }^{1}$ (D) M. Said FIDAN ${ }^{1}$ (D), Salih KAYA ${ }^{1}$ (D) Naile ANGIN² ${ }^{10}$ \\ ${ }^{1}$ Bursa Teknik Üniversitesi, Orman Fakültesi, Orman Endüstri Mühendisliği Bölümü, 16310, Bursa, Türkiye \\ ${ }^{2}$ Bursa Teknik Üniversitesi, Fen Bilimleri Enstitüsü, Biyokompozit Mühendisliği Bölümü, 16310, Bursa, Türkiye
}

\section{Eser Bilgisi / Article Info}

Araştırma makalesi / Research article DOI: 10.17474/artvinofd.492069

Sorumlu yazar / Corresponding author

Salih KAYA

e-mail: salih.kaya@btu.edu.tr

Geliş tarihi / Received

04.12 .2018

Düzeltme tarihi / Received in revised form

16.08.2019

Kabul Tarihi / Accepted

30.09.2019

Elektronik erişim / Online available

04.11.2019

\section{Anahtar kelimeler:}

Uçucu yağ

Kara ardıç

Juniperus sabina L.

Hidrodestilasyon

Mikrodalga

\section{Keywords:}

Essential oil

Black Juniper

Juniperus sabina $\mathrm{L}$.

Hidrodestilation

Microwave

\begin{abstract}
Özet
Uçucu yağlar günümüzde kozmetik, ilaç ve gıda sanayi başta olmak üzere geniş bir kullanım alanına sahiptir. Bu çalışmanın amacı mikrodalga ve hidrodestilasyon yöntemi ile kara ardıç (Juniperus sabina L.) kozalaklarından uçucu yağ elde edilerek uçucu yağ verimlerini karşılaştırmak ve GC-MS analizleri yapılarak yapısındaki bileşikler incelenmiştir. Bu çalışmada hammadde olarak kara ardıç kozalakları, uçucu yağ elde edilmesi işleminde ise mikrodalga ve hidrodestilasyon yöntemleri ile kurulan ekstraksiyon düzeneği kullanılmıştır. Mikrodalga yöntemi ile gerçekleştirilen uçucu yağ tayini deneylerinde maksimum verim \%1.37 olarak, hidrodestilasyon yöntemi ile gerçekleştirilen uçucu yağ tayini deneylerinde maksimum verim \% 1.61 olarak belirlenmiştir. Mikrodalga yöntemi ile gerçekleştirilen uçucu yağ tayini deneylerinden elde edilen uçucu yağın GC-MS analizi incelendiğinde 37 adet bileşiğe rastlandığı belirlenmiştir. Hidrodestilasyon yöntemi ile gerçekleştirilen uçucu yağ tayini deneyleri sonucunda elde edilen uçucu yağın GC-MS analizi incelendiğinde yapısında 34 adet bileşik olduğu saptanmıştır. Mikrodalga ve hidrodestilasyon yöntemi ile yapılan uçucu yağ tayini deneylerinden elde edilen uçucu yağların GC-MS analizleri incelendiğinde etken madde olarak $\alpha-$ pinen belirlenmiştir.
\end{abstract}

\begin{abstract}
Essential oils today have a wide range of uses, especially in the cosmetics, pharmaceuticals and food industries. The aim of this study is to compare essential oil yields obtained from microwave and hydrodestillation methods from juniper cones (Juniperus sabina L.) with GC-MS analysis and to investigate its structure. In this study, juniper cones were used as raw material, and extraction technique established with microwave and hydrodestillation methods was used in the process of obtaining essential oil. The maximum yield of the essential oil determination conducted with the microwave method was determined to be $1.37 \%$ and the maximum yield of the essential oil determination conducted with the hydrodestillation method was determined to be $1.61 \%$. When GCMS analysis of the essential oil obtained from the experiments of essential oil determination conducted by the microwave method was examined, it was determined that 37 compounds were found. As a result of the essential oil determination experiments carried out with hydrodestillation method, GC-MS analysis of essential oil obtained were investigated and it was found that there were 34 compounds in the structure. When GC-MS analysis of essential oils obtained from essential oil determination experiments with microwave and hydrodestillation method were investigated, $\alpha$-pinene was determined as active substance.
\end{abstract}

\section{GiRiş}

Uçucu yağlar, sekonder metabolitler olmak üzere aromatik bitkilerden elde edilen uçucu, doğal, kompleks bileşikler olarak tanımlanmaktadır. Bundan dolayı güçlü aroması terpenoidler, terpenler (monoterpenler, hemiterpenler, diterpenler ve seskiterpenler) çeşitli aromatik ve alifatik bileşiklerden (aldehitler, asitler, alkoller, laktonlar veya asiklik esterler) meydana gelmektedir (Peruç ve ark. 2018, Bakkali ve ark. 2008;
Bassoli ve Juliani 2012, Pichersky ve ark. 2006).

Antimikrobiyal aktiviteleri, fonksiyonel gruplarına, kimyasal kompozisyonlarına ve bileşenler arasındaki etkenlere bağlıdır (Peruç ve ark. 2018, Bakkali ve ark. 2008, Bassoli ve Juliani 2012, Derman ve Deans 2000). Aynı bitkinin uçucu yağları bitkinin yaşı, coğrafi konumu ve damıtma yöntemi gibi birçok faktöre göre değişiklik göstermektedir (Peruç ve ark. 2018). Uçucu yağlar sıvı-sıvı ekstraksiyonu, katı-sıvı ekstraksiyonu, su ve buhar 
distilasyonu, soxhlet ekstraksiyonu uçucu yağ eldesinde en fazla kullanılan yöntemlerdendir (Çıvğa 2015). Bu yöntemler kullanılarak aromatik bitkilerden elde edilen uçucu yağlar antioksidan ve fenolik özelliklerinden dolayı farmakolojik ve tıbbi amaçlı olarak, gıdalarda koruyucu madde olarak, bitki zararlıları ile yabancı otlara karşı herbisit olarak günümüzde geniş bir kullanım alanına sahiptir (Çıvğa 2015, Toroğlu ve Çenet 2006). Mikrodalga sistemi, yüksek ekstraksiyon verimi ve daha kısa ekstraksiyon süresi olmak üzere birçok önemli avantaj sunar (Bendahou ve ark.2007).

Ülkemizde ardıç türlerinin doğal olarak yayılış gösterdiği 7 tür, 11 farklı taksonu vardır. Bu taksonlar; J. sabina L., J. comminus var. comminus, J. excelsa subsp. polycarpus, J. comminus var. saxatilis, J. drupacea Labill., J. excelsa subsp. excelsa, J. foetidissima Willd., J. oxycedrus var. spilinanus, J. oxycedrus var. oxycedrus, J. oxycedrus var. macrocarpa, J. phoenicea L.'dir (Çıvğa 2015, Fakir 2014). Literatürde 18 ardıç türünün meyvelerinden hazırlanan uçucu yağların antioksidan, antikolinesteraz ve antimikrobiyal yönünden araştırılmıştır (Öztürk ve ark. 2010).

$\mathrm{Bu}$ çalışmanın amacı mikrodalga ve hidrodestilasyon metodları ile ardıç kozalaklarından uçucu yağ elde edilerek verimlerini karşılaştırmak ve elde edilen uçucu yağların GC-MS analizlerini incelemektir.

\section{MATERYAL ve YÖNTEM}

\subsection{Kara ardıç (Juniperus sabina L.)}

Bu çalışmada materyal olarak Bursa'nın Keles ilçesinin Belenören köyünden temin edilen kara ardıç kozalakları kullanılmıştır. Kara kozalakları haziran ayında toplandı ve teşhisi Bursa Teknik Üniversitesi Orman Fakültesi Botanik laboratuvarında yapılmıştır.

\subsection{Uçucu yağ tayini}

Uçucu yağ elde edilmesinde mikrodalga ve hidrodestilasyon yöntemleri kullanılarak uçucu yağ tayini deneyleri gerçekleştirilmiştir. Uçucu yağ tayini deneyleri sonucunda elde edilen uçucu yağların verimi aşağıdaki formülle yaş ağırlığa oranla hesaplanmıştır.

Uçucu yă̆ verimi $(\%)=\frac{U c ̧ u c u \text { yă̆ miktarl }}{\text { Örnek miktarl }} * 100$

\subsubsection{Mikrodalga yöntemi}

Mikrodalga-hidrodestilasyon sistemi ile gerçekleştirilen uçucu yağ tayini deneyleri 50 dakika 450 watt ve 10 dakika 550 watt parametrelerinde gerçekleştirilmiştir. Uçucu yağ tayini deneyleri Milestone marka Neos MA125 model cihazında gerçekleştirilmiştir.

\subsubsection{Hidrodestilasyon yöntemi}

Hidrodestilasyon yöntemi ile gerçekleştirilen uçucu yağ tayini deneylerinde mantolu ısıtıcının sıcaklığı $100{ }^{\circ} C^{\prime}$ ye getirilerek cam balondaki ardıç ve suyun kaynaması sağlandıktan sonra 2 saat süre boyunca uçucu yağ elde etme işlemi gerçekleştirilmiştir. Uçucu yağ elde etme işlemi 2 saat boyunca gerçekleştirildikten sonra deney sona erdirilmiştir. Hidrodestilasyon yöntemi ile gerçekleştirilen uçucu yağ tayini deneylerinde 500 ml'lik isolab marka mantolu ısıtıcı, 500 ml'lik isolab marka cam balon ve clevenger kullanılmıştır.

\subsection{GC-MS analizi}

Elde edilen uçucu yağların GC-MS analizi 1:20 oranında nhekzan ile seyreltme işlemi yapıldıktan sonra Agilent marka GC-MS cihazında $30 \mathrm{~m} * 0.250 \mathrm{~mm} * 0.25 \mathrm{~m} \mu$ boyutunda DB-5MS kolonda, $1 \mathrm{ml} / \mathrm{dk}$. helyum gazı akış hızında, 1:50 split oranında, $250 \stackrel{\circ}{ } \mathrm{C}$ inlet sıcaklığında, $1 \mu \mathrm{l}$ enjektör hacminde, $60{ }^{\circ} C^{\prime}$ den başlayarak $3^{\circ} \mathrm{C} / \mathrm{dk}$. Isıtma hızında $300{ }^{\circ} \mathrm{C}^{\prime}$ ye getirilmiştir ve 5 dakika bekledikten sonra analiz sonlandırılmıştır.

\section{BULGULAR VE TARTIŞMA}

\subsection{Uçucu yağ verimi}

\subsubsection{Mikrodalga yöntemi verimi}

Mikrodalga yöntemi ile gerçekleştirilen uçucu yağ tayini deneylerinde elde edilen uçucu yağların verimi Çizelge 1 'de gösterilmiştir. Mikrodalga yöntemi ile gerçekleştirilen uçucu yağ tayini deneyleri sonucu elde edilen maksimum uçucu yağ verimi \% 1.37 olarak belirlenmiştir. 
Çizelge 1: Mikrodalga (MS)ve Hidrodestilasyon sistemi (HS) ile gerçekleştirilen uçucu yağ tayini deneyleri sonucu elde edilen uçucu yağların verimi

\begin{tabular}{ccccccccc}
\hline \multirow{2}{*}{ Örnek Adı } & \multicolumn{2}{c}{ Örnek Miktarı (g) } & \multicolumn{2}{c}{ Uçucu yağ miktarı (g) } & \multicolumn{2}{c}{ Uçucu yağ verimi (\%) } & Ortalama \\
\cline { 2 - 8 } & MS & HS & MS & HS & MS & HS & MS & HS \\
\hline Kara ardıç & 200.47 & 100.22 & 2.21 & 1.62 & 1.10 & 1.61 & \\
Kara ardıç & 200.28 & 100.08 & 2.21 & 1.46 & 1.37 & 1.46 & $1.2 \pm 1.14$ \\
Kara ardıç & 200.54 & 100.08 & 2.29 & $1.52 \pm 0.07$ \\
\hline
\end{tabular}

\subsubsection{Hidrodestilasyon yöntemi verimi}

Hidrodestilasyon yöntemi ile gerçekleştirilen uçucu yağ tayini deneylerinde elde edilen uçucu yağların verimi Çizelge 1'de belirtilmiştir.

Çizelge 1'e bakıldığında hidrodestilasyon yöntemi ile gerçekleştirilen uçucu yağ tayini deneyleri sonucunda maksimum uçucu yağ verimi \%1.61 olarak tespit edilmiştir. Hidrodestilasyon yöntemi ile gerçekleştirilen uçucu yağ tayini deneyleri sonucunda elde edilen uçucu yağın verimi hidrodestilasyon yöntemi ile gerçekleştirilen uçucu yağ deneyleri sonucunda elde edilen uçucu yağın veriminden daha fazla olduğu belirlenmiştir.

\subsection{Uçucu yağın GC-MS analizi}

Mikrodalga yöntemi ile gerçekleştirilen uçucu yağ tayini deneyleri sonucunda elde edilen uçucu yağların GC-MS analiz sonuçları çizelge 2'te, kromotogramı şekil 1'de gösterilmiştir.

Çizelge 2 incelendiğinde mikrodalga yöntemi ile gerçekleştirilen uçucu yağ tayini deneyleri sonucunda elde edilen uçucu yağın GC-MS analizine bakıldığında uçucu yağın yapısında 36 adet bileşene rastlanmıştır. Etken madde olarak \% 70.26 alana sahip $\alpha$-pinen belirlenmiştir.

Çizelge 2. Mikrodalga yöntemi ile yapılan deneylerde elde edilen uçucu yağın GC-MS sonuçları

\begin{tabular}{|c|c|c|c|c|c|}
\hline \multirow{2}{*}{ Sira No } & \multirow{2}{*}{ Bileşik adı } & \multicolumn{2}{|c|}{$\%$ Alan } & \multicolumn{2}{|c|}{ Alıkonma zamanı } \\
\hline & & MS & HS & MS & HS \\
\hline 1 & Tricyclo & 0.49 & 0.54 & 5.605 & 5.610 \\
\hline 2 & alpha.-Pinene & 70.26 & 77.11 & 5.982 & 6.005 \\
\hline 3 & Camphene & 0.51 & 0.55 & 6.331 & 6.337 \\
\hline 4 & beta.-Myrcene & 3.78 & 3.41 & 7.390 & 7.396 \\
\hline 5 & 3-Carene & 1.9 & 1.75 & 8.054 & 8.059 \\
\hline 6 & 1,3-Cyclohexadiene & 0.16 & 0.18 & 8.317 & 8.328 \\
\hline 7 & o-Cymene & 0.13 & 0.12 & 8.580 & 8.586 \\
\hline 8 & D-Limonene & 2.60 & 2.16 & 8.746 & 8.757 \\
\hline 9 & beta.-Phellandrene & 0.45 & 0.47 & 8.809 & 8.815 \\
\hline 10 & gamma.-Terpinene & 1.45 & 1.39 & 9.770 & 9.782 \\
\hline 11 & 4-Carene & 2.60 & 2.27 & 10.800 & 10.806 \\
\hline 12 & Verbenol & 0.07 & & 13.203 & \\
\hline 13 & 2-Bornanone & 0.15 & 0.11 & 13.284 & 13.289 \\
\hline 14 & endo-Borneol & 0.14 & 0.11 & 14.302 & 14.308 \\
\hline 15 & 1,3,5-Undecatriene & 0.16 & 0.10 & 14.445 & 14.456 \\
\hline 16 & Terpinen-4-ol & 0.11 & 0.14 & 14.674 & 14.680 \\
\hline 17 & Cyclohexene, 1-methyl-3- & 0.09 & 0.11 & 15.292 & 15.298 \\
\hline 18 & Bicycloheptan-2-ol & 1.07 & 0.66 & 19.091 & 19.097 \\
\hline 19 & Caryophyllene & 0.14 & 0.14 & 24.750 & 24.756 \\
\hline 20 & cis-Thujopsene & 0,20 & 0,22 & 25,374 & 25,380 \\
\hline 21 & Humulene & 0,11 & 0,10 & 26,215 & 26,221 \\
\hline 22 & gamma.-Muurolene & 0,10 & 0,09 & 26,553 & 26,558 \\
\hline 23 & Bicyclohept-2-ene & 0,11 & 0,09 & 26,661 & 26,673 \\
\hline 24 & 1,6-Cyclodecadiene & 2,10 & 1,41 & 27,279 & 27,279 \\
\hline 25 & 1,3-Cyclohexadiene & 0,15 & 0,13 & 27,823 & 27,829 \\
\hline 26 & 2,4,6-Octatriene & 0,50 & 0,12 & 28,481 & 28,481 \\
\hline 27 & $1,2,3,5,6,8 a-h e x a h y d r o$ & 0.27 & 0.19 & 28.767 & 28.773 \\
\hline 28 & trans-beta-Ocimene & 0.08 & & 29.128 & \\
\hline 29 & 1H-Cyclopropazulen-4-ol & 0.45 & 0.15 & 31.748 & 31.748 \\
\hline 30 & Cedrol & 5.16 & 1.72 & 32.275 & 32.246 \\
\hline 31 & Androst-5-en-4-one & 0.11 & & 48.376 & \\
\hline
\end{tabular}




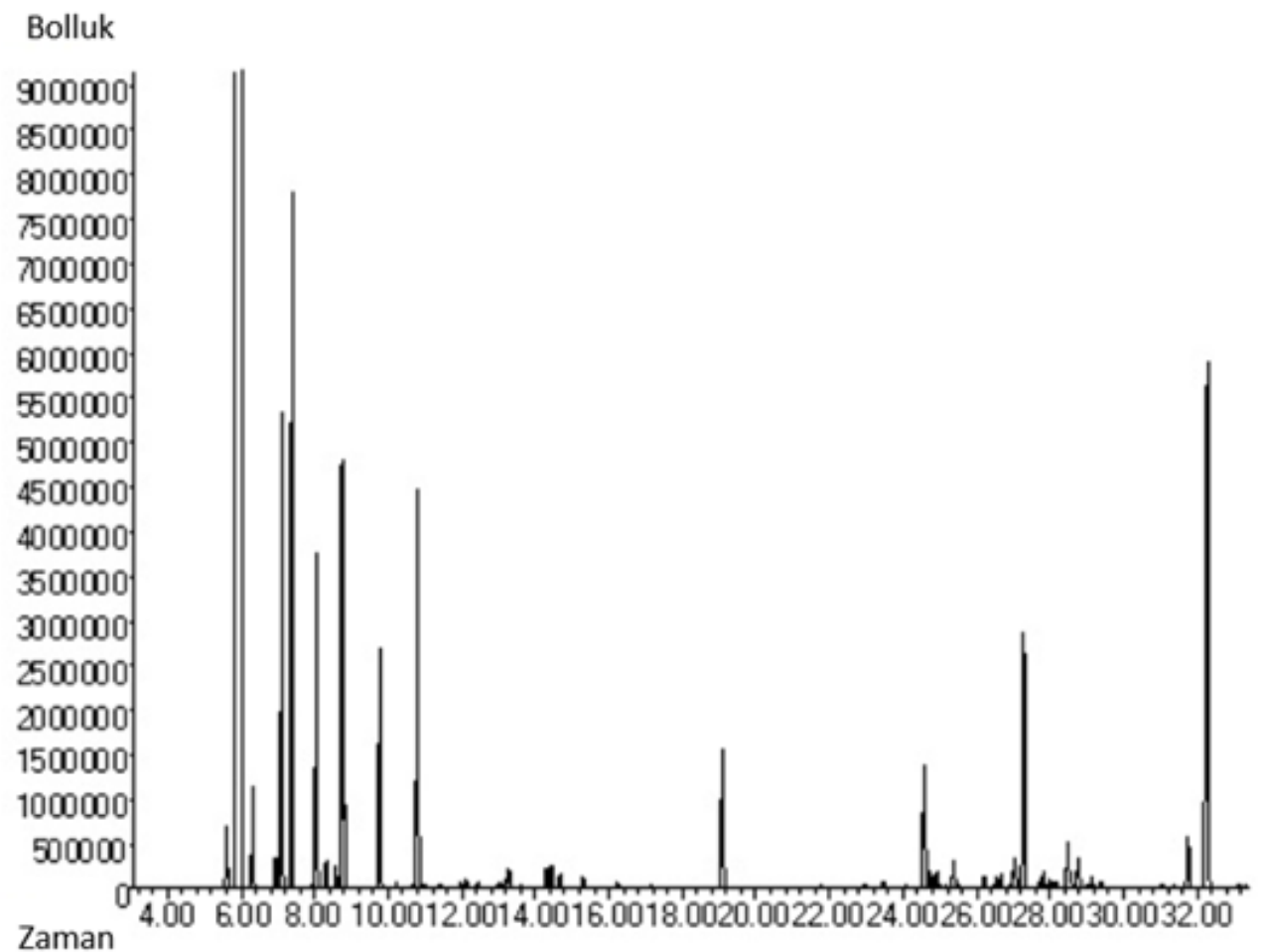

Şekil 1. Mikrodalga yöntemi ile elde edilen uçucu yağın GC-MS kromotogramı.

Hidrodestilasyon yöntemi ile gerçekleştirilen uçucu yă̆ tayini sonucunda elde edilen uçucu yağın GC-MS analizi çizelge 3'te gösterilmiştir. Hidrodestilasyon yöntemi ile gerçekleştirilen uçucu yağ tayini deneyleri sonucunda elde edilen uçucu yağın GC-MS analizi incelendiğinde 34 adet bileşik tespit edilmiştir. Etken madde olarak \% 77.11 alana sahip $\alpha$-pinen belirlenmiştir. Elde edilen sonucun literatürle uyumlu olduğu belirlenmiştir (Cosentino ve ark.). Hidrodestilasyon yöntemi ile gerçekleştirilen uçucu yağ tayini sonucunda elde edilen uçucu yağın GC-MS kromotogramı şekil 2'de gösterilmiştir.

Çizelge 3. Hidrodestilasyon yöntemi ile gerçekleştirilen uçucu yağ tayini işlemi sonucu elde edilen uçucu yağın GC-MS sonuçları

\begin{tabular}{|c|c|c|c|}
\hline Sira No & Bileşik adı & $\%$ Alan & Alıkonma zamanı \\
\hline 1 & gamma.-Terpinene & 0.54 & 5.610 \\
\hline 2 & alpha.-Pinene & 77.11 & 6.005 \\
\hline 3 & Bicycloheptane & 0.16 & 6.285 \\
\hline 4 & Camphene & 0.55 & 6.337 \\
\hline 5 & beta-Phellandrene & 0.16 & 6.944 \\
\hline 6 & beta-Pinene & 2.58 & 7.121 \\
\hline 7 & beta-Myrcene & 3.41 & 7.396 \\
\hline 8 & 3-Carene & 1.75 & 8.059 \\
\hline 9 & 4-Carene & 0.18 & 8.328 \\
\hline 10 & o-Cymene & 0.12 & 8.586 \\
\hline 11 & D-Limonene & 2.16 & 8.757 \\
\hline 12 & Bicyclohex-2-ene & 0.47 & 8.815 \\
\hline 13 & gamma-Terpinene & 1.39 & 9.782 \\
\hline 14 & Cyclohexene, 1-methyl-4 & 2.27 & 10.806 \\
\hline 15 & 2-Bornanone & 0.11 & 13.289 \\
\hline 16 & endo-Borneol & 0.11 & 14.308 \\
\hline 17 & 1,3,5-Undecatriene & 0.10 & 14.456 \\
\hline 18 & Terpinen-4-ol & 0.14 & 14.680 \\
\hline
\end{tabular}


Çizelge 3 (Devamı). Hidrodestilasyon yöntemi ile gerçekleştirilen uçucu yağ tayini işlemi sonucu elde edilen uçucu yağın GC-MS sonuçları

\begin{tabular}{cccc}
\hline Sıra No & Bileşik adı & \% Alan & Alıkonma zamanı \\
\hline 19 & alpha.-Terpineol & 0.11 & 15.298 \\
20 & Bornyl acetate & 0.66 & 19.097 \\
21 & gamma-Muurolene & 1.08 & 24.579 \\
22 & Caryophyllene & 0.14 & 24.756 \\
23 & 1 H-3a,7-Methanoazulene & 0.16 & 24.928 \\
24 & cis-Thujopsene & 0.22 & 25.380 \\
25 & Humulene & 0.10 & 26.221 \\
26 & $1,6-$ Cyclodecadiene & 0.09 & 26.558 \\
27 & Di-epi-.alpha.-cedrene & 0.09 & 26.673 \\
28 & $1,2,4$ a,5,6,8a-hexahydro-4,7-dimethyl-1 & 0.31 & 27.033 \\
29 & 1 H-Cyclopentacyclopropabenzene & 1.41 & 27.279 \\
30 & Phenol, 3-(1-methylethyl) & 0.13 & 27.829 \\
31 & $2,4,6-$ Octatriene, 3,4-dimethyl & 0.12 & 28.481 \\
32 & 1H-Cyclopropazulene & 0.19 & 28.773 \\
33 & Cedrol & 0.15 & 31.748 \\
34 & Naphthalene, $1,2,3,5,6,8$-hexahydro-4,-dimethyl-1-methylethyl) & 1.72 & 32.246 \\
\hline
\end{tabular}

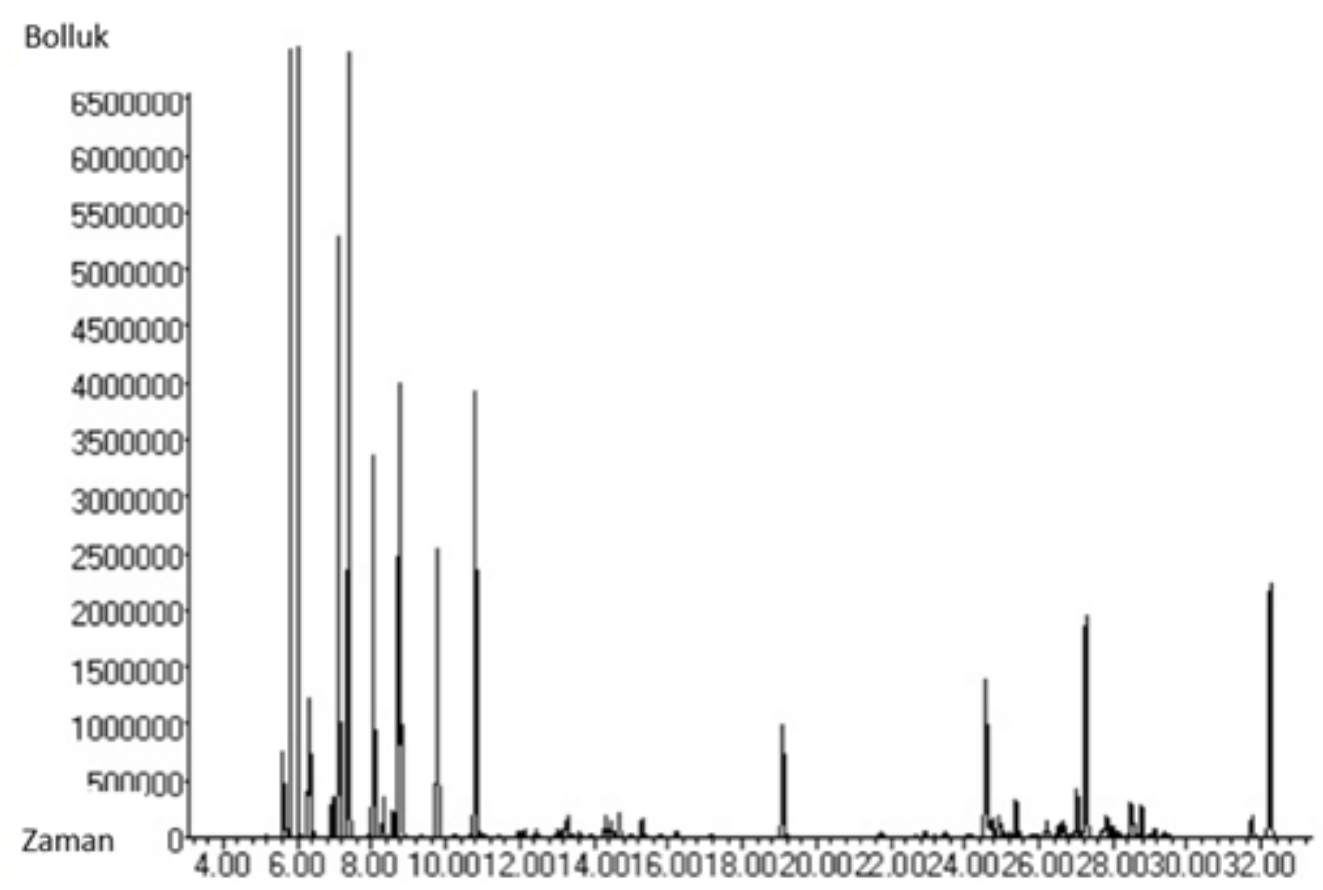

Şekil 2. Hidrodestilasyon yöntemi ile elde edilen uçucu yağın GC-MS kromotogramı

Uçucu yağların GC-MS analizleri incelendiğinde mikrodalga yöntemi ile gerçekleştirilen uçucu yağ tayini deneyleri neticesinde elde edilen uçucu yağın yapısında hidrodestilasyon yöntemi ile gerçekleştirilen uçucu yağ tayini deneylerinde elde edilen uçucu yağın yapısındakinden daha fazla bileşen rastlandığı saptanmıştır.

\section{SONUÇ}

Mikrodalga ve hidrodestilasyon yöntemleri ile gerçekleştirilen uçucu yağ tayini deneyleri sonucunda hidrodestilasyon yöntemi ile gerçekleştirilen uçucu yağ tayini deneylerinden elde edilen uçucu yağ veriminin daha fazla olduğu belirlenmiştir. Mikrodalga yöntemi ile gerçekleştirilen uçucu yağ tayini deneyleri sonucu elde edilen uçucu yağda 36 adet bileşene rastlanırken hidrodestilasyon sistemi ile gerçekleştirilen uçucu yağ tayini deneyleri sonucunda elde edilen uçucu yağda 34 adet bileşene rastlanmıştır. Mikrodalga ve hidrodestilasyon yöntemleri ile elde edilen uçucu yağların GC-MS analizleri incelendiğinde iki sistemde etken madde olarak $\alpha$-pinen belirlenmiştir. 


\section{TEŞEKKÜR}

Uçucu yağların GC-MS analizinde yardımcı olan Bursa Teknik Üniversitesi Kimya bölümü Dr. Öğr. Üyesi Burçak Kaya Özsel'e ve Arş. Gör. Berna Niş'e teşekkür ederim.

Bu makale, 4-6 Ekim 2018 tarihinde "4th International Non-Wood Forest Products Symposium"nda sözlü bildiri olarak sunularak özeti yayınlanmıştır.

\section{KAYNAKLAR}

Bakkali F, Averbeck S, Averbeck D, Idaomar M (2008) Biological effects of essential oils: a review Food Chem Toxicol, 46, pp 446-75.

Bassole IH, Juliani HR (2012) Essential oils in combination and their antimicrobial properties Molecules, 17, pp,3989-4006.

Başer KHC (1993) Essential oils of Anatolian Labiatae: A profile. Acta Horticulture. 333, pp. 217-238.

Bendahou M., Muselli A., Grignon-Dubois M., Benyoucef M.,Desjobert J.-M. (2007) Antimicrobial activity and chemical composition of Origanum glandulosum Desf. essential oil and extract obtained by microwave extraction: Comparison with hydrodistillation, Food Chemistry 106, 132-139.
Cosentino S., Barra A., Pısano B., Cabızza M., Pırısı F., Palması F., (2003) Composition and Antimicrobial Properties of Sardinian Juniperus Essential Oils against Foodborne Pathogens and Spoilage Microorganisms, Journal of Food Protection, 7, Pages 1288-1291

Çıvğa A, (2015) Diken ardıç (Juniperus oxycedrus L.) kozalaklarının uçucu yağ özellikleri ve çevresel faktörlerle ilişkileri. Süleyman Demirel Üniversitesi Fen bilimleri enstitüsü Yüksek lisans tezi, Isparta,111s.

Dorman HJ, Deans SG (2000) Antimicrobial agents from plants:antibacterial activity of plant volatile oils. J Appl Microbiol,88,pp.308-16.

Fakir H (2014) Türkiye'nin doğal egzotik ağaç ve çalıları. 1. TC Orman ve Su İşleri Bakanlığı Orman Genel Müdürlüğü Yayınları.1, pp. 115174.

Öztürk M., Tümen I., Uğur A., Aydoğmuş-Öztürk F., Topçu G., (2010) Evaluation of fruit extracts of six Turkish Juniperusspecies for their antioxidant,anticholinesterase and antimicrobial activities, J Sci Food Agric, 91, 867-876

Peruc D, Gobin I, Abram M, Broznic D., Svalina T, Stifter S, Staver MM, Ticac B (2018) Antimycobacterial potential of the juniper berry essential oil in tap water, Arh Hig Rada Toksikol., vol. 69, pp.46 54.

Pichersky E, Noel JP, Dudareva N (2006) Biosynthesis of plant volatiles: nature's diversity and ingenuity, Science,311, pp.808-11.

Toroğlu S, Çenet M (2006) Tedavi amaçlı kullanılan bazı bitkilerin kullanım alanları ve antimikrobiyal aktivitelerinin belirlenmesi için kullanılan metodlar. Kahramanmaraş Sütçü İmam Üniversitesi Fen ve Mühendislik Dergisi, 9, pp. 12-20. 